Original Research Paper

\title{
Synthesis and Characterization of Cobalt, Iron and Ruthenium Catalysts for the Production of Synthetic Diesel
}

\author{
${ }^{1}$ Dayna M. Ortiz Rodríguez, ${ }^{1}$ María del C. Cotto-Maldonado, \\ ${ }^{1}$ José Duconge Hernández, ${ }^{2}$ Carmen Morant and ${ }^{1}$ Francisco M. Márquez-Linares \\ ${ }^{I}$ Nanomaterials Research Group-NRG, Department of Chemistry and Physics, School of Natural Sciences and Technology, \\ Universidad Ana G. Méndez-Gurabo Campus, 189 St. Rd. km 3.3, 00778-Gurabo, PR, USA \\ ${ }^{2}$ Department of Applied Physics, Universidad Autónoma de Madrid, 28049-Cantoblanco, Madrid, Spain
}

\author{
Article history \\ Received: 06-02-2020 \\ Revised: 03-03-2020 \\ Accepted: 20-04-2020 \\ Corresponding Author: \\ Dayna M. Ortiz Rodríguez \\ Nanomaterials Research Group- \\ NRG, Department of Chemistry \\ and Physics, School of Natural \\ Sciences and Technology, \\ Universidad Ana G. Méndez- \\ Gurabo Campus, 189 St. Rd. \\ km 3.3, 00778-Gurabo, PR, \\ USA \\ Email: dortiz23@email.uagm.edu
}

\begin{abstract}
Fossil fuels are currently the world's leading source of energy. Environmental legislations, the high price of fossil fuels, the concern about the supply of these fuels and technological development, makes it necessary to search for alternative sources of energy. The production of clean liquid fuels, such as synthetic diesel from synthesis gas, by FischerTropsch (FT) method, is considered a very appropriate strategy for the solution of some of the inconveniences shown by fossil fuels. This method consists in the catalytic transformation of a gaseous mixture of $\mathrm{CO}$ and $\mathrm{H}_{2}$ into liquid fuels with variable chain lengths. The fuels produced by this process are clean, since they do not have aromatic compounds, sulphur or nitrogen-based compounds, preventing the production and release of NOx and SOx during combustion. FT processes involve the use of heterogeneous catalysts based on active metals (i.e., $\mathrm{Co}, \mathrm{Ru}$ or $\mathrm{Fe}$ ) highly dispersed on the surface of appropriate supports. In the present investigation, the synthesis of new catalysts has been carried out to produce synthetic diesel by means of FT processes. For this, spherical $\mathrm{SiO}_{2}$ particles have been used as support, on which nanoparticles of the different metals have been dispersed. The activity and selectivity of the synthesized catalysts was evaluated in FT processes under different experimental conditions.
\end{abstract}

Keywords: Synthetic Diesel, $\mathrm{SiO}_{2}$ Support, Fischer-Tropsch, Hydrocarbon Fractions, Selectivity, Catalytic Activity

\section{Introduction}

Currently, mainly energy resources from nonrenewable energy sources or fossil fuels (oil, coal or natural gas) are used. In the coming years, a significant increase in the global consumption of liquid fuels, derived from fossil resources, is estimated to increase from about 95 million barrels per day (b/d) in 2015 to 113 million b/d in 2040 (EIA, 2017).

Fossil fuels (petroleum, natural gas and coal) accounted for about $79 \%$ of total U.S. primary energy production in 2018 (EIA, 2019a). This massive consumption permanently leads to significant pollution problems arising from the presence of sulfur and nitrogen, which are released into the atmosphere during combustion in the form of $\mathrm{SO}_{2}$ and nitrogen oxides (NOx), among other contaminants. These emissions have harmful effects on the environment, such as acid rain and the presence of greenhouse gases, responsible for global warming and climate change, among many others (EPA, 2017; Mohajan, 2018; EPA, 2019). The release of these pollutants into the atmosphere has been linked to certain health problems such as lung disease, heart failure, increased risk of certain types of cancer and, in the worst case, death (CDCP, 2019). According to the report of the Intergovernmental Panel on Climate Change (IPCC) in 2004, the current life and that of future generations will depend largely on the replacement of polluting energy sources (coal, oil, gas, nuclear) with clean alternatives and respectful with biological ecosystems (solar, wind, biomass, etc.) (Sims et al., 2011).

The US Energy Information Administration (EIA) in 2019, forecasts renewables will be fastest growing source of electricity generation, becoming an important component of the energy supply (EIA, 2019b). The increasingly demanding environmental legislation, 
health problems, the constant increase in fossil fuel prices, the increase in demand and its limited availability, the concern of governments to guarantee the security of fuel supply and technological development, make the search for alternative sources of renewable energy necessary. In this sense, viable technologies with high commercial value can be introduced for the production of clean liquid fuels such as synthetic diesel, which is relevant in a sustainable energy scenario.

\section{Synthesis of Fischer Tropsch (FT)}

One of the most viable technologies for the production of synthetic diesel fuel is the synthesis of Fischer-Tropsch (FT), which can be developed by a catalytic process from a mixture of carbon monoxide $(\mathrm{CO})$ and hydrogen $\left(\mathrm{H}_{2}\right)$, or syngas (Van de Loosdrecht et al., 2013), The FT process allows complex mixtures of straight and branched chain hydrocarbons to be obtained, as well as oxygenated products such as alcohols, aldehydes, ketones and esters, although most are linear paraffins and $\alpha$-olefins (Shafer et al., 2019). Some of the paraffins obtained can be used in the pharmaceutical, cosmetic or lubricant industry, although the main application of waxes produced by FT processes is to obtain synthetic fuels such as gasoline and diesel (Eslava, 2017). The molecular weight range of the hydrocarbons obtained includes products in the gas phase $\left(\mathrm{C}_{1}-\mathrm{C}_{4}\right)$, liquid hydrocarbons $\left(\mathrm{C}_{5}-\mathrm{C}_{18}\right)$ and waxes $\left(\mathrm{C}_{19+}\right)$. The hydrocarbon fraction from $\mathrm{C}_{5}$ is especially relevant in the energy sector, since it is the fraction corresponding to diesel fuel (Huffman, 2003).

Experimentally, FT processes produce a wide range of $\mathrm{C}_{1}-\mathrm{C}_{50+}$ hydrocarbons, being one of the biggest challenges of this process to find catalysts that selectively produce the desired product, or fraction of product (Jahangiri et al., 2014). FT catalysts must meet the following characteristics: (1) Ability to form metal carbonyls; (2) high activity in hydrogenation reactions; and (3) the operating conditions of the FT process must not be very far from those under which metal carbonyls are produced (Fierro et al., 2003).

The metals that combine activity in the dissociation of $\mathrm{CO}$ and $\mathrm{H}_{2}$ and that are active in the conversion of syngas, are mainly $\mathrm{Fe}, \mathrm{Co}, \mathrm{Ni}, \mathrm{Ru}$ and $\mathrm{Rh}$. However, Ni and $\mathrm{Rh}$ are not suitable for FT processes, since, in addition to other inconveniences, they produce methane (Steen and Claeys, 2008; Vannice, 1975). Although catalysts for FT based on $\mathrm{Co}, \mathrm{Fe}$ and $\mathrm{Ru}$ have been developed, it is considered that, due to the high activity, high selectivity to linear products, greater stability against deactivation, low activity towards the change of water gas and low cost, cobalt catalysts are clearly preferred for these processes (Wook et al., 2009).
One of the required characteristics of these catalysts is that they must have a high surface area. The material used as support, which in our case was $\mathrm{SiO}_{2}$, is of great importance since it influences the dispersion, the size of the metal particles and the activity. The support allows to favor the dispersion of the active metal, maximizing the available surface area of the metal and reducing the amount required, which is of relevance due to the high cost of some of these metals (Dry, 2002).

The FT process represents a clear alternative for the production, not only of clean fuel worldwide but also of other liquid products with high added value. Given the shortage of oil and the need to implement new environmental requirements worldwide, FT technology can be considered as a real research alternative that focuses on improving the efficiency and selectivity of catalysts, reaction media, pressure-temperature conditions, the $\mathrm{H}_{2} / \mathrm{CO}$ ratio and the design of better industrial reactors. As these conditions are optimized, the FT process will be more commercially competitive.

\section{Methodology}

\section{Synthesis of Silicon Oxide Microspheres as Support}

The synthesis of $\mathrm{SiO}_{2}$ microspheres was carried out by the Stöber-Fink-Bohn (SFB) method, which consists in the hydrolysis and condensation of a silicon precursor in a water/alcohol solution as a solvent, using a basic catalyst (Márquez and Roque, 2006).

The first stage of the synthesis (Fig. 1), consists in the controlled hydrolysis of a silicon precursor (tetraethyl orthosilicate, TEOS). The addition of TEOS causes the formation of a white precipitate $\left(\mathrm{SiO}_{2}\right)$. This stage occurs in the presence of ultrafiltered deionized water (D.I.U.F. water), this reagent being the one that will limit the final yield of the process. The presence of an alcohol (ethanol) in defined proportions and of a catalyst (ammonium hydroxide, $\mathrm{NH}_{4} \mathrm{OH}$ ), will be essential to obtain amorphous silicon oxide (Valtchev and Tosheva, 2013).

In a second stage (Fig. 1), condensation occurs, giving rise to micrometric particles of silicon oxide. The silicon oxide support can form nano or microspheric particles of controlled dimensions during the synthesis process, which can range between $30 \mathrm{~nm}$ and $1 \mu \mathrm{m}$ in diameter (Márquez and Roque, 2004, 2005, 2006). It is important to mention that the distribution and size of the $\mathrm{SiO}_{2}$ microspheres will depend on the precursor, catalyst, temperature and solvent used (Valtchev and Tosheva, 2013).

The synthesis of $\mathrm{SiO}_{2}$ microspheres was carried out according to the SFB method (Valtchev and Tosheva, 2013; Stöber et al., 1968), at temperatures of $20^{\circ} \mathrm{C}, 30^{\circ} \mathrm{C}$ and $40^{\circ} \mathrm{C}$. The proportions of each reagent were adjusted to be able to have the highest yield in each of the processes. 


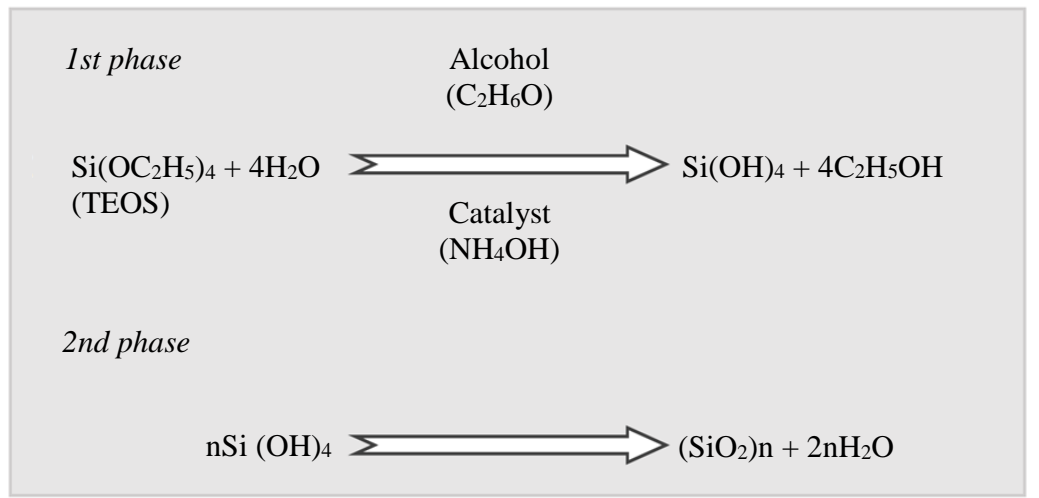

Fig. 1: Mechanism for the synthesis of $\mathrm{SiO}_{2}$ particles, using the Stöber-Fink-Bohn (SFB) procedure

\section{Dispersion of the Metal Precursor on the Support}

The dispersion of metals was carried out by wet impregnation. In a typical synthesis, $20 \mathrm{~mL}$ of the previously prepared solution of the metal precursor (cobalt (II) chloride, iron (III) chloride, or ruthenium (III) chloride) was introduced into a $50 \mathrm{~mL}$ Erlenmeyer flask at concentrations of $0.0150 \mathrm{M}$ or $0.030 \mathrm{M}$ and at different temperatures $\left(20^{\circ} \mathrm{C}, 30^{\circ} \mathrm{C}\right.$ or $\left.40^{\circ} \mathrm{C}\right)$. Subsequently, $0.1 \mathrm{~g}$ of the $\mathrm{SiO}_{2}$ support was added and the mixture was homogenized by magnetic stirring for 1 h. The reaction mixture was transferred to a beaker and allowed to evaporate in an oven at $60^{\circ} \mathrm{C}$ for $12 \mathrm{~h}$.

The material obtained from each precursor was calcined in air in a muffle (Thermolyne-Eurotherm 2116), at $300^{\circ} \mathrm{C}$ for $15 \mathrm{~min}$ (Márquez and Roque, 2004, $2005,2006)$. The calcination process allowed to obtain the oxides of the different metals on the $\mathrm{SiO}_{2}$ support. Subsequently, the material obtained was reduced in flowing hydrogen $(300 \mathrm{sccm})$ at $600^{\circ} \mathrm{C}$, for $20 \mathrm{~min}$, using a Carbolite tube furnace (Márquez and Roque, 2004, 2005, 2006). As a result, metallic nanoparticles of cobalt, iron or ruthenium, dispersed on the surface of the support, were obtained.

\section{Results Obtained}

\section{$\mathrm{SiO}_{2}$ Support Characterization}

More than 90 different syntheses of the $\mathrm{SiO}_{2}$ support were performed under different experimental conditions (concentration, catalyst, or temperature) obtaining average diameters ranging from $0.056 \mu \mathrm{m}$ to $0.473 \mu \mathrm{m}$. For this investigation, the one that showed the greatest surface area was selected as support material.

Figure 2 shows some Scanning Electron Microscopy (SEM) images corresponding to the synthesis of $\mathrm{SiO}_{2}$, at $20^{\circ} \mathrm{C}, 30^{\circ} \mathrm{C}$ and $40^{\circ} \mathrm{C}$. As can be seen, spherical particles of micrometric size were obtained in all cases, quite homogeneous in size and with little agglomeration.

\section{Characterization of Active Metals}

Figure 3 shows SEM images ( $a$ and $b)$ and Transmission Electron Microscopy (TEM) images (c and d) of $\mathrm{SiO}_{2}$ microparticles with different active metals of $\mathrm{Co}$ and $\mathrm{Ru}$, synthesized at $0.0150 \mathrm{M}$ and $40^{\circ} \mathrm{C}$.

Figures $3 \mathrm{a}$ and $3 \mathrm{~b}$ show catalysts with a homogeneous spherical morphology. The metal nanoparticles of $\mathrm{Ru}$ and $\mathrm{Co}$ can be clearly seen in the TEM images (Fig. 3c and 3d). In all cases, the average diameters of the metal particles are below $10 \mathrm{~nm}$. The distribution and size of these metal particles are the most relevant factors, together with the specific area of the material, to justify the catalytic activity of these catalysts (Naito et al., 2018).

The specific area of the catalysts synthesized under different concentration and temperature conditions was characterized by the BET method (Table 1).

As shown in Table 1, surface areas showed very high values for all catalysts. However, the largest areas were observed for Co catalysts.

\section{Catalytic Tests}

Fischer-Tropsch catalytic activity tests were carried out in a fixed bed reactor at a temperature of $493 \mathrm{~K}$ and a pressure of 10 bar. The catalyst was diluted in $\mathrm{SiC}$ and a reaction mixture of $\mathrm{H}_{2}: \mathrm{CO}: \mathrm{Ar}=6: 3: 1(\mathrm{v} / \mathrm{v} / \mathrm{v})$ was used, with a molar ratio $\mathrm{H}_{2} / \mathrm{CO}=2$. The space velocity was 13 $\mathrm{L}\left(\mathrm{CO}+\mathrm{H}_{2}\right) /($ gcat $\bullet h)$. The catalysts were reduced in situ at $400^{\circ} \mathrm{C}$ for $6 \mathrm{~h}$ in $\mathrm{H}_{2}$ flow. The FT reaction products were measured by Gas Chromatography (GC), using a triple column system (Porapak Q, Molecular Sieve 13X, fused silica WCOT) and TCD and FID detectors. Three hydrocarbon fractions were studied, corresponding to $\mathrm{C}_{1^{-}}$ $\mathrm{C}_{3}, \mathrm{C}_{4}-\mathrm{C}_{5}$ and $\mathrm{C}_{6+}$. These hydrocarbon fractions indicate the number of carbon atoms generated by the FT process.

Figure 4 shows the catalytic results obtained for the analyzed hydrocarbon fractions, with $\mathrm{Co}, \mathrm{Fe}$ and $\mathrm{Ru}$ catalysts prepared at concentrations of $0.0150 \mathrm{M}$ and $0.030 \mathrm{M}$ and at different synthesis temperatures $\left(20^{\circ} \mathrm{C}\right.$, 
$30^{\circ} \mathrm{C}$ and $\left.40^{\circ} \mathrm{C}\right)$. As can be seen in Fig. 4a, at concentrations of $0.0150 \mathrm{M}$ and $0.030 \mathrm{M}$ synthesized at $20^{\circ} \mathrm{C}$, the Fe catalyst obtained greater selectivity to $\mathrm{C}_{1-}$ $\mathrm{C}_{3}$ short chain products, followed by $\mathrm{Co}$ and $\mathrm{Ru}$, respectively. Similarly, at the concentration of $0.0150 \mathrm{M}$ at $20^{\circ} \mathrm{C}$, it is observed that the $\mathrm{Fe}$ catalyst, obtained greater selectivity to $\mathrm{C}_{4}-\mathrm{C}_{5}$ products, followed by $\mathrm{Co}$ and $\mathrm{Ru}$, respectively. On the other hand, at $0.030 \mathrm{M}$ and $20^{\circ} \mathrm{C}$, it was observed that the Co catalyst obtained greater selectivity to $\mathrm{C}_{4}-\mathrm{C}_{5}$ fractions, followed by $\mathrm{Ru}$ and
Fe, respectively. Finally, at the same experimental conditions, the $\mathrm{Ru}$ catalyst obtained the highest selectivity to $\mathrm{C}_{6+}$ long chain products; followed by $\mathrm{Co}$ and $\mathrm{Fe}$, respectively.

Figure $4 \mathrm{~b}$ and $4 \mathrm{c}$ show that at concentrations of 0.015 $\mathrm{M}$ and $0.030 \mathrm{M}$ and $30^{\circ} \mathrm{C}$ and $40^{\circ} \mathrm{C}$ respectively, the $\mathrm{Ru}$ catalyst obtained greater selectivity to $\mathrm{C}_{1}-\mathrm{C}_{3}, \mathrm{C}_{4}-\mathrm{C}_{5}$ products. At the same experimental conditions, $\mathrm{Co}$ catalysts showed the highest selectivity for $\mathrm{C}_{6+}$ long chain products.

Table 1: Specific surface area (BET) $\left(\mathrm{m}^{2} / \mathrm{g}\right)$ of catalysts synthesized at $20^{\circ} \mathrm{C}$ and $40^{\circ} \mathrm{C}$, at $0.0150 \mathrm{M}$ and $0.030 \mathrm{M}$

\begin{tabular}{|c|c|c|c|c|c|}
\hline \multicolumn{3}{|c|}{ Analysis of the specific surface area $(\mathrm{BET}) \mathrm{m}^{2} / \mathrm{g}$ at $20^{\circ} \mathrm{C}$} & \multicolumn{3}{|c|}{ Analysis of the specific surface area $(\mathrm{BET}) \mathrm{m}^{2} / \mathrm{g}$ at $40^{\circ} \mathrm{C}$} \\
\hline Catalyst & $0.0150 \mathrm{M}$ & $0.030 \mathrm{M}$ & Catalyst & $0.0150 \mathrm{M}$ & $0.030 \mathrm{M}$ \\
\hline $\mathrm{Co} @ \mathrm{SiO}_{2}$ & 448 & 352 & $\mathrm{Co} @ \mathrm{SiO}_{2}$ & 467 & 456 \\
\hline $\mathrm{Fe} @ \mathrm{SiO}_{2}$ & 405 & 343 & $\mathrm{Fe} @ \mathrm{SiO}_{2}$ & 453 & 438 \\
\hline $\mathrm{Ru} @ \mathrm{SiO}_{2}$ & 401 & 337 & $\mathrm{Ru} @ \mathrm{SiO}_{2}$ & 412 & 426 \\
\hline
\end{tabular}

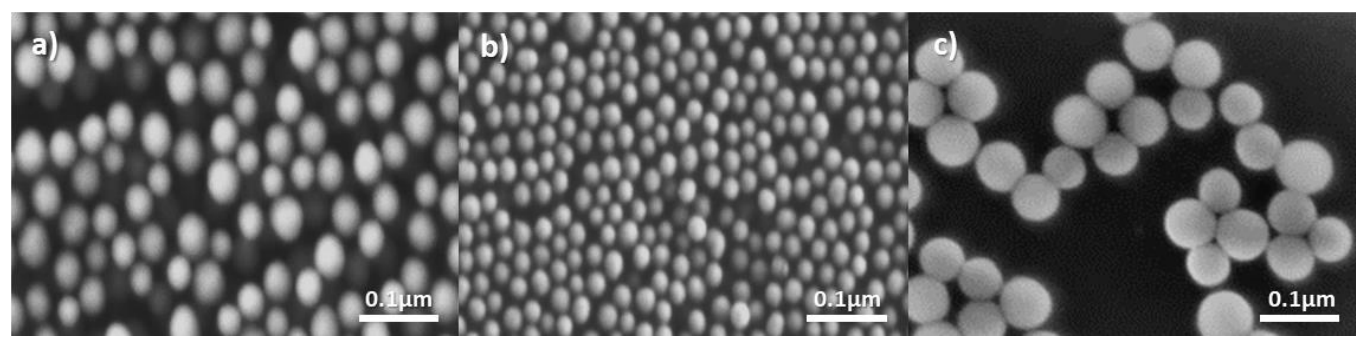

Fig. 2: SEM micrographs of $\mathrm{SiO}_{2}$ microspheres synthesized at $20^{\circ} \mathrm{C}(\mathrm{a}) ; 30^{\circ} \mathrm{C}$ (b); and $40^{\circ} \mathrm{C}$ (c)

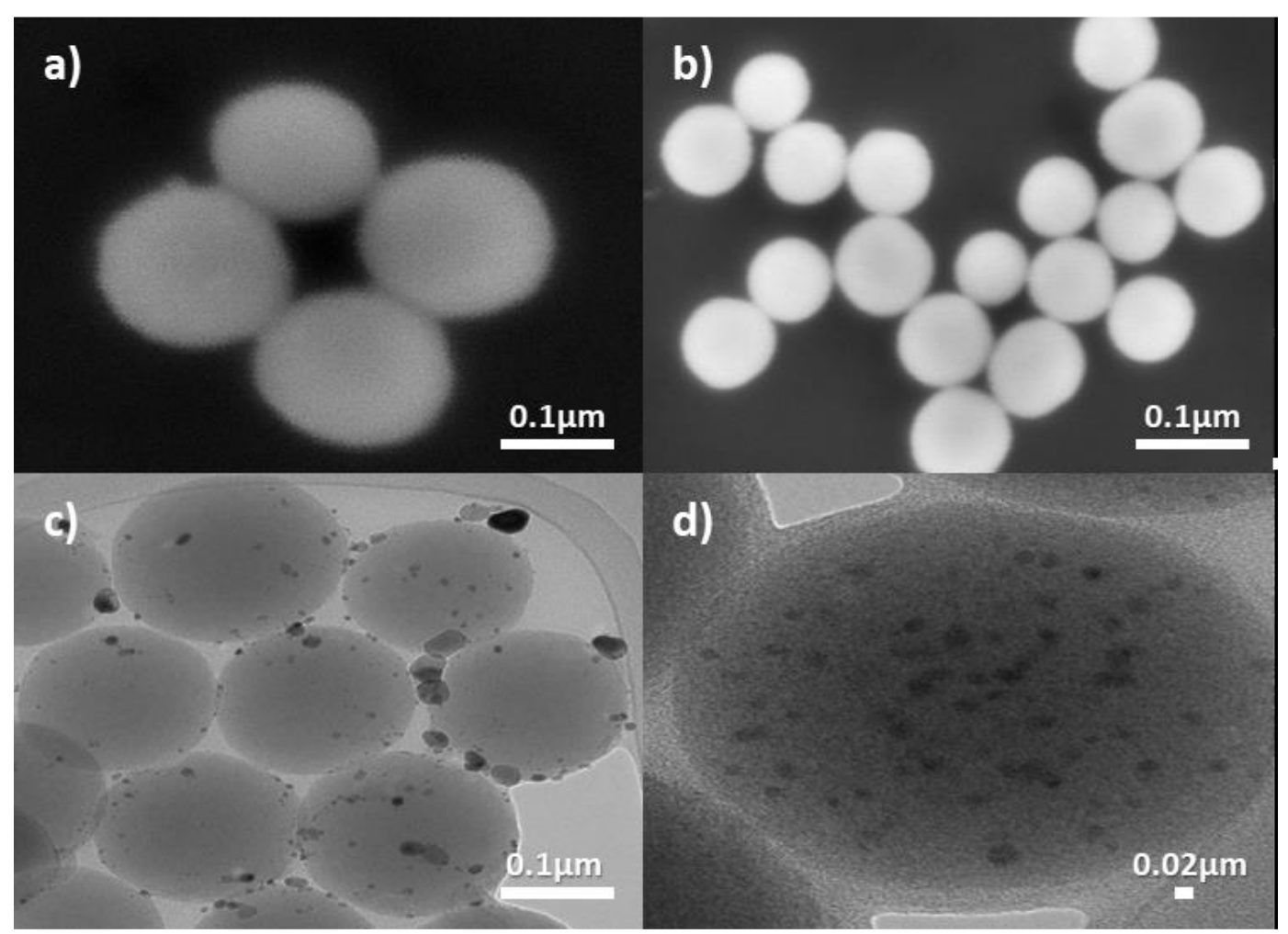

Fig. 3: $\mathrm{SEM}$ micrographs of $\mathrm{Ru} @ \mathrm{SiO}_{2}$ (a) and $\mathrm{Co} @ \mathrm{SiO}_{2}$, (b); and TEM micrographs of $\mathrm{Ru} @ \mathrm{SiO}_{2}$ (c) and $\mathrm{Co} @ \mathrm{SiO}_{2},(\mathrm{~d})$ 


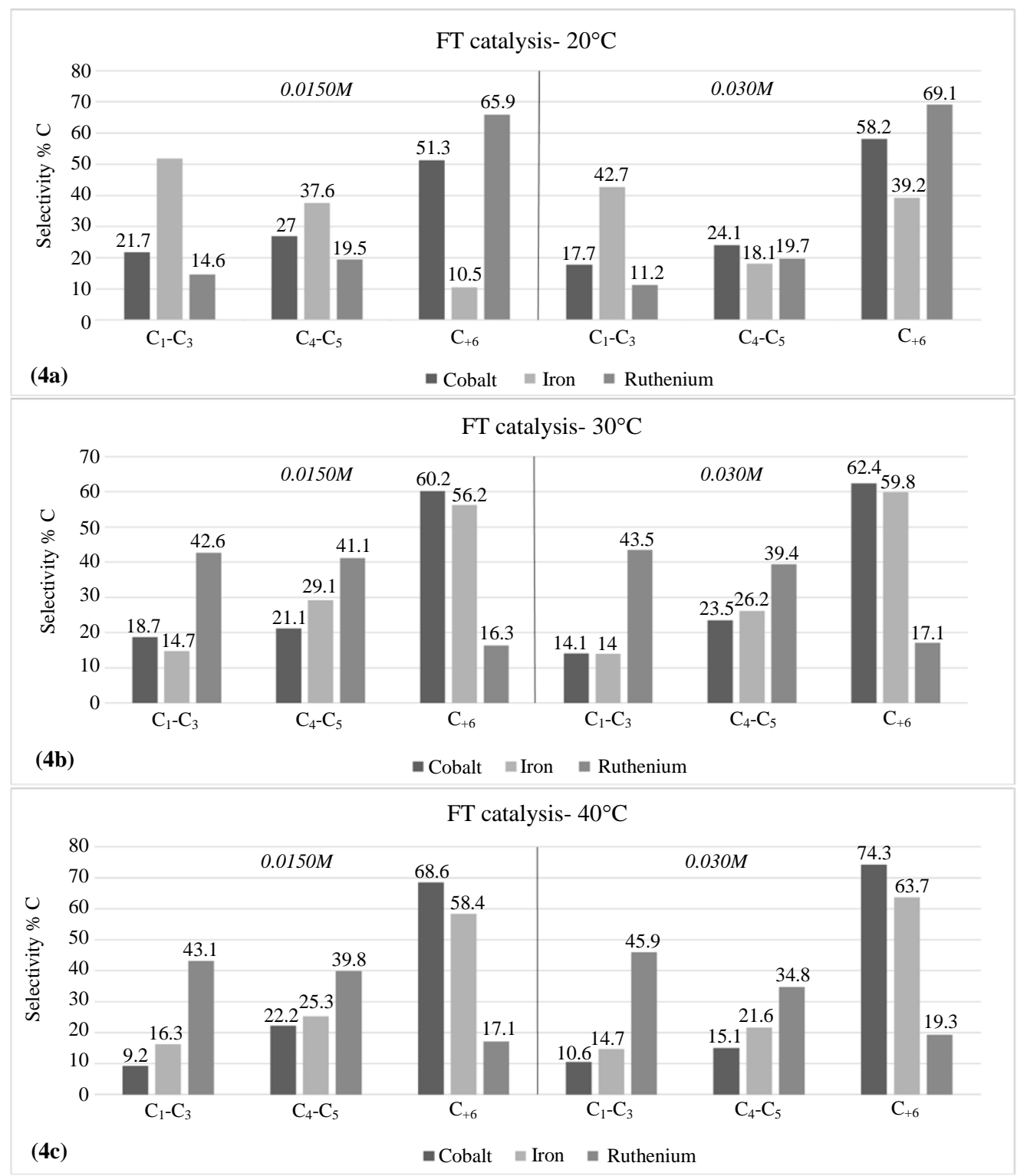

Fig. 4: Catalytic activity of $\mathrm{Co}, \mathrm{Fe}$ and Ru catalysts synthesized from concentrations of $0.015 \mathrm{M}$ and $0.030 \mathrm{M}$ at $20^{\circ} \mathrm{C}(\mathrm{a}) ; 30^{\circ} \mathrm{C}(\mathrm{b})$ and $40^{\circ} \mathrm{C}$ (c)

\section{Conclusion}

The results obtained show a clear selectivity to short chain hydrocarbons (olefins and paraffins) in catalysts whose supports were synthesized at low temperatures $\left(20^{\circ} \mathrm{C}\right.$ and $\left.30^{\circ} \mathrm{C}\right)$. On the other hand, this selectivity changes to long chain hydrocarbons (diesel fraction) when the catalysts were prepared at higher temperatures $\left(40^{\circ} \mathrm{C}\right)$.

As mentioned earlier, the $\mathrm{C}_{6+}$ fraction is the most interesting, since it is the fraction corresponding to diesel. The Co catalyst achieved the highest selectivity for long chain $\left(\mathrm{C}_{6+}\right)$ products, especially at $40^{\circ} \mathrm{C}$, compared to the $\mathrm{Ru}$ catalyst. The $\mathrm{Ru}$ catalyst was expected to show optimum performance and better results for the $\mathrm{C}_{6+}$ fraction, especially at $40^{\circ} \mathrm{C}$. However, the best results were found in $\mathrm{Co}$ and $\mathrm{Fe}$, respectively. These results are certainly interesting because $\mathrm{Ru}$ is an expensive metal and the manufacture of these Ru-based catalysts entails a very high economic expense, but this is not the case for Co and Fe catalysts.

The results obtained may be influenced by the synthesis temperature and the specific areas of the different catalysts. In fact, the Co catalyst is the one that shows the greatest area and the best results, compared to the $\mathrm{Fe}$ and $\mathrm{Ru}$ catalysts. Although the results obtained are promising, additional studies are needed to understand how small changes in the synthesis 
temperature of the $\mathrm{SiO}_{2}$ support can affect the area of the material and, therefore, the catalytic behavior of the materials obtained.

\section{Acknowledgement}

The authors thank the Puerto Rico Energy Center (PREC), Universidad Autónoma de Madrid (UAM), University of Puerto Rico (UPR-Cayey) and Center for Materials Science and Engineering-CMSE at Massachusetts Institute of Technology-MIT for the use of their characterization facilities.

\section{Funding Information}

Financial support from the U.S. Department of Defense under Grant W911NF-14-1-0046 and from the US Department of Energy and the Consortium for Integrating Energy System in Engineering and Science Education, CIESESE (DENA0003330), are gratefully acknowledged.

\section{Author's Contributions}

All authors contributed equally to this work.

\section{Ethics}

This article is original and contains unpublished material. The corresponding author confirms that all of the other authors have read and approved the manuscript and no ethical issues involved.

\section{References}

CDCP, 2019. Air contaminants. Centers for Disease Control and Prevention.

Dry, M., 2002. The Fischer-Tropsch process: 19502000. Catalysis Today, 71: 227-241. DOI: 10.1016/S0920-5861(01)00453-9

EIA, 2017. Petroleum and other liquids. International Energy Outlook, U.S. Energy Information Administration.

EIA, 2019a. Today in energy. Energy Information Administration.

EIA, 2019b. U.S. energy facts explained. Consumption and Production, International Energy Outlook, U.S. Energy Information Administration.

EPA, 2017. Climate change science. Causes of Climate Change. United States Environmental Protection Agency.

EPA, 2019. The sources and solutions: Fossil fuels United States environmental protection agency.

Eslava, J., 2017. Fischer-Tropsch synthesis over carbon supported Ru-based catalyst. PhD Thesis, Universidad Autónoma de Madrid, Madrid, España.
Fierro, J., P. Terreno, M. Granados, M. Ojeda and F. Pérez, 2003. La Síntesis de Hidrocarburos Fischer Tropsch. Retos y Perspectivas. Anales Quím. Real Sociedad Española de Química.

Huffman, G., 2003. C1 chemistry for the production of ultra-clean liquid transportation fuels and hydrogen. U.S. Department of Energy Office of Scientific and Technical Information, United States.

Jahangiri, H., J. Bennett, P. Mahjoubi, K. Wilson and S. $\mathrm{Gu}$, 2014. A review of advanced catalyst development for Fischer-Tropsch synthesis of hydrocarbons from biomass derived SYN-gas. Catalysis Sci. Technol., 4: 2210-2229.

DOI: $10.1039 / \mathrm{c} 4 \mathrm{cy} 00327 \mathrm{f}$

Márquez, F. and R. Roque, 2006. Synthesis and characterization of large specific surface area nanostructured amorphous silica materials. J. Nanosci. Nanotechnol., 6: 1-5.

DOI: $10.1166 /$ jnn.2006.166

Márquez, F. and R. Roque, 2004. Synthesis and characterization of silica microsphere-based mesoporous materials. Mater. Sci. Semiconductor Process., 7: 467-469.

DOI: 10.1016/j.mssp.2004.09.092

Márquez, F. and R. Roque, 2005. Synthesis and characterization of silica sphere-packing mesoporous materials. Surface Interface Anal., 37: 393-397. DOI: 10.1002/sia.2011

Mohajan, H., 2018. Acid rain is a local environment pollution but global concern. Open Sci. J. Analytical Chem., 3: 47-55.

Naito, M., T. Yokoyama, K., Hosokawa and K. Nogi, 2018. Nanoparticle Technology Handbook. 3rd Edn., Elsevier, Amsterdam, ISBN-13: 978-0-444-64110-6, pp: 904.

Shafer, W., M. Kumaran, U. Graham, J. Yang and C. Masuku et al., 2019. Fischer-Tropsch: Product selectivity-the fingerprint of synthetic fuels. Catalysts, 9: 259-259. DOI: 10.3390/catal9030259

Sims, R., P. Mercado, W. Krewitt, G. Bhuyan and D. Flynn et al., 2011. Integration of Renewable Energy into Present and Future Energy Systems. In: Renewable Energy Sources and Climate Change Mitigation. Special Report of the Intergovernmental Panel on Climate Change, Edenhofer, O., R. PichsMadruga, Y. Sokona, K. Seyboth and P. Matschoss et al. (Eds.), Cambridge University Press, Cambridge, New York, USA, ISBN-13: 978-1-107-02340-6, pp: 608-706.

Steen, E. and M. Claeys, 2008. Review: Fischer-Tropsch catalysts for the biomass to liquid process. Chem. Eng. Technol., 31: 655-666.

DOI: $10.1002 /$ ceat. 200800067 
Stöber, W., A. Fink and E. Bohn, 1968. Controlled growth of monodisperse silica spheres in the micron size range. J. Colloid Interface Sci., 26: 62-69.

DOI: 10.1016/0021-9797(68)90272-5

Valtchev, V. and L. Tosheva, 2013. Porous nanosized particles: Preparation, properties and applications. Chem. Rev., 113: 6734-6760.

DOI: $10.1021 / \mathrm{cr} 300439 \mathrm{k}$

Van de Loosdrecht, J., F.G. Botes, I.M. Ciobica, A. Ferreira and P. Gibson et al., 2013. Fischer-Tropsch Synthesis: Catalysts and Chemistry. In: Comprehensive Inorganic Chemistry II: From Elements to Applications, Reedijk, J.A. and K. Poeppelmeyer (Eds.), Elsevier, Amsterdam, pp: 525-557.
Vannice, M., 1975. The catalytic synthesis of hydrocarbons from $\mathrm{H}_{2} / \mathrm{Co}$ mixtures over the group VIII metals: I. The specific activities and product distributions of supported metals. J. Catalysis, 31: 449-461.

Wook, J., K. Seung, S. Hwan, K. Chary and Y. Lee et al., 2009. Effect of support and cobalt precursors on the activity of $\mathrm{Co} / \mathrm{AlPO}_{4}$ catalysts in Fischer-Tropsch synthesis. J. Molecular Catalysis A: Chem., 311: 7-16. DOI: 10.1016/j.molcata.2009.07.011 